www.jmscr.igmpublication.org

Impact Factor (SJIF): 6.379

Index Copernicus Value: 79.54

ISSN (e)-2347-176x ISSN (p) 2455-0450

crossrefDOI: https://dx.doi.org/10.18535/jmscr/v6i8.35

\author{
Journal Of Medical Science And Clinical Research \\ IGM Publication \\ An official Publication of IGM Publication
}

\title{
Study of urinary Albumin creatinine ratio in smoker and non-smoker diabetes mellitus patients
}

\author{
Authors \\ Dr Pankaj Bhushan, MD (Biochemistry) ${ }^{1}$, Dr Usha Kumari, DGO; MD (Biochemistry) ${ }^{2}$ \\ ${ }^{1}$ Tutor, Department of Biochemistry, J.L.N. M.C.\& H, Bhagalpur, India \\ ${ }^{2}$ Assistant Professor, Department of Biochemistry, J.L.N. M.C.\& H, Bhagalpur, India
}

\section{Introduction \& Review of literature}

Diabetes Mellitus is a group ofdisease causing metabolic hyperglycemia leads to macrovascular and microvascular complications causing significant morbidity and mortality among diabetic people. Etiologically, Type 1 Diabetes Mellitus is characterized by P-cell destruction caused by an autoimmune process, usually leads to absolute insulin deficiency where as Type-2 Diabetes Mellitus is characterized by insulin resistance in peripheral tissues and an insulin secretory defect of the B-cell.According to WHOglobally, the number of people with diabetes is expected to rise up to 300 million (prevalence rate $5.4 \%$ ) by the year 2025. According to Joshi. SR (Diabetes care in India) diabetes mellitus has emerged as a major health problem in India. There are 66.8 million people with diabetes in India in 2015 and this number is predicted to rise up to 70 million by 2025 . By that time every fifth diabetic person will be an Indian. Therefore, Joshi SR et al (2007) stated India - "Diabetic Capital of the world."Diabetic Nephropathy, retinopathy and neuropathy are most common complications of uncontrolled diabetes mellitus. The risk of chronic complication in diabetic patients depend on duration of hyperglycemia and usually manifested after 10 years. Diabetic Nephropathy is one of the common causes of morbidity and mortality in diabetic patients. Pathogenesis of Diabetic glomerulopathy is due to (a) formation of advanced glycation end products (b) Activation of protein kinase-c and (c) Intra cellular hyperglycemia with disturbance in polyol pathway. Advanced glycation end products (AGEs) are formed as a result of non-enzymatic reactions between intracellular glucose derived dicarbonyl precursors with amino group of both intracellular and extracellular protein and promote glomerular dysfunctions .In the capillaries of renal glomeruli albumin binds to the glycated basement membrane causing increased basement membrane thickening which is characteristic of diabetic microangiopathy. The capillaries of glomeruli with the thickened basement membrane are more leaking than normal capillaries to the plasma proteins. The microangiopathy is the basic pathogenesis for development of diabetic nephropathy. "Proteinuria" refers to increase in urinary excretion of albumin and other specific protein or total protein where as "Albuminuria" refers to increase in urinary excretion of albumin specifically. "Microalbuminuria" refers to albumin excretion above the normal range 30 to 
$300 \mathrm{mg} / \mathrm{d}$ but below the level of detection by test for total protein.It is a known fact that the smoking increases the risk of diabetic nephropathy and causes microalbumineria. Albumen creatinine ratio increases in Type 1 Diabetes mellitus and Type 2 Diabetes both. However, the increase in this ratio is high in cases of smokers of both types of diabetes mellitus than the non-smoker subjects. This indicates that there are development of some pathology in renal system due to tobacco toxins causing damage to the renal tubular epithelium and glomerular epithelium. This damage is greater in cases of diabetes mellitus patients if they are smokers. Chase et al (1991) also found that in type 1 diabetic smokers abnormal albumin exertion risk was increased 2.8 times. Rossing et al (2002) found that smoking increases the risk of progression from Microalbuminuria to overt Proteinuria

\section{Aims and Objectives}

Diabetes mellitus is the major health problem in India. It is established fact that the tobacco toxins increases the risk of renal damage and therefore increases the albumin creatinine ratio also.

In this study we observed that the risk is more in cases of smokers. In our view it is essential to prevent the progression of renal damages and other complications of diabetic patient by teaching them not to smoke and to control their blood glucose within normal limits by changing personal habits (like no smoking).

\section{Materials and Method}

The present study has been conducted with the main objective of estimating albumin creatinine ratio (urinary albumin: urinary creatinine) in patients of diabetes mellitus of type 1 and type- 2 in smoker and non-smoker groups. The place of the study was Department of Biochemistry, J. L. N Medical College, Bhagalpur, Bihar, India.

Material: Total 100 cases having diabetes mellitus were suffering from the disease for 10 years or more and 50 cases of normal healthy individuals were selected from medical outdoor and indoor Department of Medicine JLNMC Bhagalpur.

\section{Inclusion criteria}

100 cases of known diabetes mellitus were categorized into Type-I Diabetes Mellitus 45 and Type-II Diabetes Mellitus 55 cases. Each cases of Type I DM again grouped as smokers 21 cases and 24 cases ofnon-smokers. Similarly the type-II Diabetes Mellitus were also grouped into two smokers numbered 26 cases and non smokers 29 case. These cases were compaired with the normal person having no diabetes and non-smokers. There were 50 normal healthy individuals of both sexes, ranges of age from 20-50 years were selected for control.

\section{Exclusion criteria}

1- Cases having Proteinuria detectable by dipstick tests.

2- Cases having any evidence of infection established by of estimation:

a.Spot urinary albumin

b.Spot urinary creatinine

c.Fasting plasma glucose

d.R/E of urine

e.Urine $\mathrm{C} / \mathrm{S}$ test etc.

\section{Methodology}

\section{Collection of urine sample}

Urine sample were collected in clean, sterile plastic container. Collected urine sample were tested by dipsticks for the presence of frank Proteinuria

Dipstick negative urine sample were used for quantization of albumin and creatinine within 4 hours of voiding.

\section{Collection of Blood sample}

Blood samples were collected after 12 hours of fasting. Approximately $1 \mathrm{ml}$ of venous blood drawn. It was transferred to sodium fluoride vial and then mixed gently then it was centrifuged at $3000 \mathrm{rpm}$ for 5 minutes. Plasma was pipetted out and kept in a clean steriale vial. 


\section{Method of urinary Albumin Estimation}

Urinary albumin was estimated by immuno turbidimetric method (Bio Systems' Costa Brava, 30 Bance- kiba (Spain)
Method of urinary creatinine Estimation

Urinary creatinine is estimated by Modified Jaffe Method.

Fasting Plasma Glucose were estimated by GOD-POD Method.

\section{Observation}

Table-1 Showing the distribution of cases.

\begin{tabular}{|c|c|c|}
\hline Group & Type of cases & No. of cases \\
\hline I & Control & 50 \\
\hline II & Type 1 diabetes mellitus & 45 \\
\hline III & Type 2 diabetes mellitus & 55 \\
\hline Total: & & 150 \\
\hline
\end{tabular}

Table -2 Showing the number of cases, means, standard deviation and standard error of mean value, $t$ - value and p-values of Albumin creatinine ratio with cases of smokers and non-smokers diabetics.

\begin{tabular}{|c|c|c|c|c|c|c|c|c|}
\hline Group & Habit & $\begin{array}{c}\text { No. of } \\
\text { cases }\end{array}$ & $\begin{array}{c}\text { Mean of } \\
\text { ACR }\end{array}$ & SD & SEM & ' $t$ ' & 'p' & Remarks \\
\hline \multirow[t]{2}{*}{$\begin{array}{l}\text { Type } 1 \text { diabetes } \\
\text { mellitus }\end{array}$} & $\begin{array}{c}\text { Smokers } \\
\text { Non-smokers }\end{array}$ & 21 & 75.00 & $\begin{array}{l}41.82 \\
25.10\end{array}$ & 9.13 & \multirow[t]{2}{*}{3.76} & \multirow[t]{2}{*}{$<0.001$} & \multirow[t]{2}{*}{$\mathrm{S}$} \\
\hline & & 24 & 35.63 & & 5.12 & & & \\
\hline \multirow{2}{*}{$\begin{array}{l}\text { Type } 2 \text { diabetes } \\
\text { mellitus }\end{array}$} & Smokers & 26 & 76.23 & 27.26 & 5.41 & \multirow{2}{*}{9.12} & \multirow{2}{*}{$<0.001$} & \multirow{2}{*}{$\mathrm{S}$} \\
\hline & Non-smokers & 29 & 25.45 & 3.18 & $\theta .59$ & & & \\
\hline
\end{tabular}

Table- 2 shows statistically significant $(\mathrm{P}<0.001)$ difference in mean albumin- creatinine ratio values in smokers and non-smokers in type-I DM cases. Table 2 also shows significant $(\mathrm{P}<\mathrm{O} .001)$ difference in mean albumin- creatinine ratio in smokers and non-smokers in type-2 DM cases.

\section{Discussion and Result}

In (Table - 2) 21 cases of type I diabetes mellitus who were smokers, the mean albumin creatinine ratio was found to be 75.00 while in 24 cases of diabetes mellitus who were non-smokers, the mean albumin creatinine ratio was found to be 35.63 .

When the difference of mean albumin creatinine ratio was compared between smoker and nonsmoker patients of type I diabetes mellitus, it was found to be statistically significant $(\mathrm{p}<0.001)$.

In 26 cases of type 2 diabetes mellitus who were smokers, the mean albumin creatinine ratio was found to be 76.23 while in 29 cases of type 2 diabetes mellitus who were non-smokers, the mean albumin creatinine ratio was found to be 25.45 .
When the difference of mean albumin creatinine ratio was compared between smoker and nonsmoker type- II diabetic patients, it was found to be statistically significant ( $\mathrm{p}<0.001$ ).

Red hill et al., (1989) concluded that smoking is associated with high amounts of carboxyhaemoglobin and decreased oxygen delivery to tissue; Albuminuria in smokers may be caused by hypoxia in the renal microcirculation.

Chase et al (1991) found that in type I diabetic smoker's abnormal albumin excretion risk was increased 2.8 times.

Gambaro et al., (2001) identified smoking as an important risk factor for the development and progression of Microalbuminuria in type 2 diabetes mellitus patients. Rossing et al (2002) found that smoking increases the risk of progression from Microalbuminuria to overt Proteinuria. In our study Table-2 shows statistically significant $(\mathrm{P}<0.001)$ difference in mean albumin -creatinine ratio in smokers and non-smokers in type-1 DM.Table-2 also shows significant $(\mathrm{P}<0.001)$ difference in mean albumin 
creatinine ratio in smokers and non- smokers in type-2 DM.

\section{Conclusion}

We concluded that the person who is smoker \& diabetic, more high risk cases for developing kidney damage by nephropathy. This is clearly indicated by an increase in urinary albumin and creatinine ratio in group smokes with diabetes mellitus type $1 \& 2$ both.

Therefore we advice the person who are high risk cases for developing DM should never be smokers because smoking itself is one of the major risk factor for development of Nephropathy in diabetic patients.'

\section{Bibliography}

1. Joshi SR (diabetes care in India ) 2015

2. Joshi SR.J. Assoc Physicians India; 55:323-24,2007

3. Rossing et al. Diabetes Care; 25:85964,2002

4. Gambaro et al. Diabetes Nutr Metrab; 14:337-42,2001

5. Chase et al. JAMA; 265;614-17,1991

6. Redhilet al. Clin Physiol; 9:242-248, 1989. 